
L. A. Schwarte
C. J. Zuurbier
C. Ince

\title{
Mechanical ventilation of mice
}

\begin{abstract}
Due to growing interest in murine functional genomics research, there is an increasing need for physiological stable in vivo murine models. Of special importance is support and control of ventilation by artificial respiration, which is difficult to execute as a consequence of the small size of the animal and the technically demanding breathing pattern. In addition, numerous genetically altered mice show depressed spontaneous ventilation or impaired respiratory responses. After an introduction in murine respiratory physiology we describe options for ventilatory support, its monitoring and the potential side effects. This review will provide an overview on current possibilities in the field of airway support in mouse research.
\end{abstract}

Key words Mouse - respiration - ventilatory support mechanical ventilation - respiratory monitoring

Received: 30 March 2000

Returned for revision: 13 June 2000

Revision received: 4 August 2000

Accepted: 9 August 2000

L. A. Schwarte · C. J. Zuurbier · C. Ince $(\bowtie)$

Department of Anaesthesiology

Academic Medical Center

University of Amsterdam

Meibergdreef 9

1105 AZ Amsterdam, The Netherlands

\section{A. Schwarte}

Center for Anaesthesiology

Heinrich-Heine-University

Moorenstraße 5

40225 Düsseldorf, Germany

\section{Introduction}

Due to the growing interest in mouse research (e.g., the expanding field of functional genomics), there is an emerging need for physiological relevant, stable in vivo murine models, often requiring ventilatory support. Many techniques available for in vivo research of larger animals have been miniaturized and adapted, ranging from vascular catheterization to measurement of cardiac output and organ blood flows. A major difficulty in this process of miniaturization is encountered at the level of mechanical ventilation, mainly because of the small size of mice and the technically demanding murine breathing pattern. This view, therefore, summarizes the current state of mechanical ventilation of mice.

Several aspects of murine respiratory support will be discussed: mouse respiratory physiology, indications of when to use mechanical ventilation in mice, airway access, types of ventilation of the mouse, and monitoring and side effects of mechanical ventilation.

\section{Respiratory physiology in mice}

Physiological values for murine respiratory parameters (e.g., "normal" or "standard" values) given in the literature are divergent. This is mainly caused by technical difficulties in the measurement of these variables (10), the large inter-strain variability (51) and differences in experimental conditions (e.g., free moving vs. restrained) (8).

\section{Neonate mice}

Newborn mice have, depending on birth weight (0.5-1.5 g), a ventilatory tidal volume $(\mathrm{Vt})$ of 5-20 $\mu \mathrm{l}(27)$. For neonate hybrid-mice (129Sv/J x ICR, $1.17 \mathrm{~g}$ body weight) a respiratory 
rate (RR) of $79 \mathrm{~min}^{-1}$, a ventilatory tidal volume (Vt) of $25 \mu 1$, an inspiratory fraction (inspiratory to total time of the respiratory cycle, $\mathrm{Ti} / \mathrm{Tt}$ ) of 0.44 and a resulting ventilatory minute volume (Ve) of $1.98 \mathrm{ml} \cdot \mathrm{min}^{-1}$ was found. Similar values are found for wild type and endothelin-1 knock-out mice $\left(\mathrm{ET}^{(--)}\right)$ when birth was achieved by cesarean section (30). Rather low respiratory values were found in a study comparing wild type neonates with littermates deficient for the RET-protooncogene: RR ranged from 28-40 $\mathrm{min}^{-1}$, Vt from 7-10 $\mu \mathrm{l}$ and VE from $0.26-0.32 \mathrm{ml} \cdot \mathrm{min}^{-1}$, with no significant differences between the groups. The authors suggest that a reduced body temperature in their setting contributed to their findings (4). With respect to control of breathing, newborn wild type mice (1 $\mathrm{g}$ bodyweight) show similar ventilatory responses to hypercapnia compared to other newborn mammals (34). Neonates deficient in endothelin-1 (129Sv/J x ICR, ET-1 $\left.{ }^{(-/)}\right)$have an attenuated ventilatory response to hypoxia and hypercapnia, compared to their wild type littermates (30). A significantly reduced ventilatory response to hypercapnia was also found in neonate mice deficient in the RET-protooncogene, compared to wild type littermates, whereas no consistent differences were obtained during hypoxic challenge (4).

\section{Adult mice}

Parameters for the spontaneous ventilation of adult mice are given in Table 1, where the following characteristics of mice ventilation are given: $\mathrm{RR}=180-270 \mathrm{ml} \cdot \mathrm{min}^{-1}, \mathrm{Vt}=0.1-0.2$ $\mathrm{ml}$ and $\mathrm{Ti} / \mathrm{Tt}=0.30-0.35$.

Little information is currently available on the lung mechanics of mice (37). Murine lung-thorax compliance was measured in pancuronium-relaxed, mechanically ventilated mice (BALB/c, no weight stated) in the range of 31-38 $\mu \mathrm{l}$ $\left(\mathrm{cmH}_{2} \mathrm{O}\right)^{-1}$ under control conditions, and $12 \mu \mathrm{l}\left(\mathrm{cmH}_{2} \mathrm{O}\right)^{-1}$ after experimental surfactant inactivation (50). Respiratory system resistance was measured in age matched $\mathrm{A} / \mathrm{J}-$ and $\mathrm{C} 3 \mathrm{H} / \mathrm{HeJ}-$ mice, revealing significant strain differences under baseline conditions ( 1 vs. $2 \mathrm{cmH}_{2} \mathrm{O} \cdot \mathrm{m}^{-1} \cdot \mathrm{s}^{-1}$ ) and especially after i.v. acetylcholine treatment ( 3 vs. $15 \mathrm{cmH}_{2} \mathrm{O} \cdot \mathrm{m}^{-1} \cdot \mathrm{s}^{-1}$ ) (11). In the same study, significant differences were also found for the respiratory system elastance under both conditions $(25 \mathrm{vs} .30 \mathrm{~cm}$ $\mathrm{H}_{2} \mathrm{O} \cdot \mathrm{ml}^{-1}$ at baseline and 28 vs. $95 \mathrm{~cm} \mathrm{H}_{2} \mathrm{O} \cdot \mathrm{ml}^{-1}$ after i.v. acetylcholine). Again, one has to realize that marked differences exist between mouse strains in respect to respiratory physiology and pathophysiology.

Divergent data is available on physiologic values for murine arterial blood gasses, regarded as the gold standard for the evaluation of adequacy of ventilation. Information on tissue $P \mathrm{O}_{2}$ of the mouse indicates that it fits within the normal mammalian range (53). Later it was suggested that mice have considerably lower alveolar and arterial $\mathrm{PCO}_{2}$ than other mammals, as low as $20 \mathrm{mmHg}$ (at pH 7.4) (31). Indeed, recent data support these lower $\mathrm{PCO}_{2}(24 \mathrm{mmHg}$ in chronically instrumented 129SV/J x ICR mice (30), $34 \mathrm{mmHg}$ in chronically instrumented C57BL/6 mice (39)). Although effects of

Table 1 Reported variables of spontaneous respiration of adolescent and adult mice.

\begin{tabular}{|c|c|c|c|c|c|c|c|}
\hline Mouse strain & bw $[\mathrm{g}]$ & Condition & $\mathrm{RR}\left[\mathrm{min}^{-1}\right]$ & $\mathrm{Vt}[\mathrm{ml}]$ & $\mathrm{Ti} / \mathrm{Tt}$ & $\mathrm{Ve}\left[\mathrm{ml} \cdot \mathrm{min}^{-1}\right]$ & Ref. [No.] \\
\hline wild type & (adult) & $(?)$ & $84-230$ & $0.09-0.23$ & $(?)$ & $11-36$ & (19) \\
\hline $129 \mathrm{~Sv} / \mathrm{J} \times \mathrm{ICR}$ & 37.9 & restrained & 195 & 0.12 & 0.47 & 24.0 & (30) \\
\hline $\mathrm{CF}-1$ & 25.0 & restrained & 272 & 0.12 & $(?)$ & 32.6 & (38) \\
\hline $\mathrm{C} 3 \mathrm{H} / \mathrm{HeJ}$ & 23.5 & unrestr. & 177 & 0.24 & 0.32 & 24.7 & (51) \\
\hline $\mathrm{AKR} / \mathrm{J}$ & 29.7 & unrestr. & 222 & 0.29 & 0.29 & 37.1 & (51) \\
\hline $129 / \mathrm{J}$ & 18.1 & unrestr. & 230 & 0.17 & 0.29 & 23.2 & (51) \\
\hline $\mathrm{DBA} / 2 \mathrm{~J}$ & 25.1 & unrestr. & 237 & 0.19 & 0.37 & 26.6 & (51) \\
\hline $\mathrm{BALB} / \mathrm{cJ}$ & 22.1 & unrestr. & 241 & 0.17 & 0.31 & 23.9 & (51) \\
\hline $\mathrm{A} / \mathrm{J}$ & 22.9 & unrestr. & 247 & 0.19 & 0.29 & 28.9 & (51) \\
\hline SJL/L & 22.3 & unrestr. & 266 & 0.14 & 0.33 & 23.2 & (51) \\
\hline C57BL/6J & 23.4 & unrestr. & 272 & 0.16 & 0.29 & 25.5 & (51) \\
\hline wild type & 30.0 & $(?)$ & 180 & 0.15 & $(?)$ & 27.0 & (13) \\
\hline $\mathrm{BALB} / \mathrm{c}$ & $22-26$ & restrained & 307 & $(?)$ & 0.47 & $(?)$ & (10) \\
\hline $\mathrm{BALB} / \mathrm{c}$ & $22-26$ & restr.+rsv & 420 & (?) & 0.33 & (?) & (10) \\
\hline C57BL/6 & $(?)$ & unrestr. & 210 & (?) & $(?)$ & (?) & (55) \\
\hline overex.Gsa & (?) & unrestr. & 269 & $(?)$ & (?) & (?) & (55) \\
\hline wild type & (?) & $(?)$ & $(?)$ & (?) & (?) & $0.72 *$ & (5) \\
\hline wild type & (?) & $(?)$ & (?) & (?) & (?) & $1.1-1.3^{*}$ & (12) \\
\hline ICR pregnant & 46 & $(?)$ & $(?)$ & $(?)$ & $(?)$ & $3.5^{*}$ & (14) \\
\hline ICR non-pregn. & 35 & (?) & (?) & $(?)$ & (?) & $3.0 *$ & (14) \\
\hline wild type & $20-40$ & unrestr. & $94-163$ & $(?)$ & (?) & (?) & (20) \\
\hline
\end{tabular}

If body weight was unknown (*), then Ve is expressed in $\left[\mathrm{ml} \cdot \mathrm{g}^{-1} \cdot \mathrm{min}^{-1}\right]$ otherwise as $\left[\mathrm{ml} \cdot \mathrm{min}^{-1}\right]$ with the bodyweight given. $b w$ bodyweight, $R R$ respiratory rate, $V t$ tidal volume, $T i / T t$ inspiratory fraction, $V e$ minute volume, $R e f$. reference, $r s v$ respiratory syncytial virus-infection 
instrumentation $(30,39)$ or restrainment cannot completely be excluded in these studies, the data does indicate a lower $\mathrm{PaCO}_{2}$ for the mouse, e.g., compared to mammals ranging from rats to humans $\left(\mathrm{PaCO}_{2} 33-41\right.$ and $35-45 \mathrm{mmHg}$ respectively).

\section{Mechanical ventilation}

\section{Indications for mechanical ventilation}

Mechanical mouse ventilation is indicated unter the following circumstances. First, the "anesthesiological" indication: one of the major goals of anesthesia is achievement of more controlled experimental conditions, including the inhibition of spontaneous movements and stable cardiovascular parameters. However, it is important to realize that all potent sedative, anesthetic or analgesic drugs used in mice cause depression of spontaneous ventilation, e.g., RR and Vt. Although these drugs might decrease ventilatory requirements by reduction of metabolism, this does not compensate for the depression of spontaneous ventilation. This mismatch of metabolism and ventilation may lead to hypoxia, hypercapnia, acidosis and consecutive disturbances of the homeostasis. Recently this has been confirmed in CD-1 mice (anesthesia with $350 \mathrm{mg} \cdot \mathrm{kg}^{-1}$ chloralhydrate and xylazine $4 \mathrm{mg} \cdot \mathrm{kg}^{-1}$ i.p.), where spontaneously breathing mice became hypoxic $\left(\mathrm{PaO}_{2}=60 \mathrm{mmHg}\right)$, hypercapnic $\left(\mathrm{PaCO}_{2}=62 \mathrm{mmHg}\right)$ and acidotic $(\mathrm{pH}=7.2)$, whereas values for the mechanically ventilated mice where markedly more physiological $\left(\mathrm{PaCO}_{2}=43 \mathrm{mmHg}, \mathrm{PaO} \mathrm{O}_{2}=\right.$ $82 \mathrm{mmHg}, \mathrm{pH}=7.3$ ) (36). Especially when a surgical procedure is finished (actual mismatch of anesthesia depth and arousing noxious stimulus), there is a considerable risk of apnea. Even if only ventilatory depression occurs, severe changes of the homeostasis may take place. Therefore, monitored mechanical ventilation supports the maintenance of a physiological relevant, stable murine model (7). Control of the ventilatory parameters is especially important in research using genetically altered mice. These are often more sensitive to standard laboratory procedures (39) and/or have specific alterations in their control of breathing. Typical examples for this are the obese leptin-deficient mice $\left(\operatorname{Lep}^{\mathrm{ob}}\right)$, showing signs of respiratory depression already in the awake state $(39,52)$, mice lacking the brain derived neurotropic factor BDNF (1), RET-protooncogene deficient mice with depressed ventilatory response (4), and endothelin-1 deficient mice with altered blood gas-values (e.g., significantly lower $\mathrm{PO}_{2}$ than wild type littermates) and impaired respiratory response to hypoxia and hypercapnia (30). However, it is often unknown when during development and under which conditions alterations occur in the respiratory system or the control of breathing (27). Also among inbred wild type strains the control of respiration differs substantially, e.g., the C57BL/6-strain was classified as highly responsive to hypercapnia, whereas the DBA/2-strain was highly responsive to hypoxia (51). Therefore, in these animals mechanical ventilation offers the possibility to study effect of differences in genetic background independent of changes in ventilation. Second, the "surgical" indication: certain surgical procedures have an improved outcome or can only be performed with support of mechanical ventilation. Examples are the bilateral ligation of the carotid artery (36), where non-ventilated mice often die from respiratory disturbances, or the growing field of cardiac research that needs an open-chest murine model $(15,18,29,44)$. Hereby opening of the thorax and the adherent interpleural space induces lung collapse with respiratory insufficiency, whereas with support of a mechanical respirator the lungs can be inflated and ventilated.

\section{Airway access in mice}

There are several possibilities of accessing and maintaining the airway in mice. In early studies using a mechanical ventilator with active in- and expiration for mice (28), the airway was accessed by advancing a tube through the mouth into the pharynx, but not further into the trachea. Although technically less demanding than endotracheal intubation, this attempt risked gastric gas-insufflation (including aspiration of stomach content) and did not provide PEEP capability. A different, nontraumatizing mode to access the airways is performed with the Brady-Newsom apparatus (3): it consists of a gas-chamber around the murine head, sealed at the thorax by a tight neoprenecollar. Elevating the pressure in this chamber leads to increased airway pressures, with respect to ambient air. Thus this concept provides continuous positive airway pressure (CPAP) if the mouse ventilates spontaneously, or mechanical ventilation, if periodic pressure changes in the chamber are generated. Although this apparatus has advantages, e.g., the technically less demanding airway access, it is also hampered with the disadvantage of gastic gas insufflation and aspiration of gastric content. To circumvent this problem, mechanical ventilation of mice today is usually performed after securing the airways by orotracheal intubation or via tracheotomy and consecutive endotracheal intubation. Tracheotomy has been performed in preterm neonate mice ( $1.15 \mathrm{~g}$ bodyweight) with insertion of polyethylene tubes (SP8, Natsume, Tokyo, Japan; tapered $0.4 \mathrm{~mm}$ outer diameter (OD)) (30), whereas for adult mice the OD of the endotracheal tube ranges from $0.9 \mathrm{~mm}$ (25-38 g mice) (29) to $1.1 \mathrm{~mm}$ (20-35 g mice) (15).

For experiments requiring recovery after surgery, temporary orotracheal intubation is performed, ideally via direct laryngoscopy with a purpose-made laryngoscope (13). The visualization of relevant airway structures requires a strong small-focus light-source, allowing transillumination of the laryngeal cavity (with vocal cords and tracheal orifice), when 
put on the ventral cervical region from the outside (2). Orotracheal intubation is performed with or without visual confirmation of the tube's tip-position (tube position judged by respiratory excursions). Visualization of the trachea (after surgical access to the deeper cervical structures) and controlled advancement of the endotracheal tube allows more accurate positioning of the tube, but is more invasive and has therefore an increased morbidity and mortality.

For animals sacrificed at the end of the experiment, direct surgical access to the airways is an alternative option. Since most of our mouse surgeries require preparation of deeper cervical structures (e.g., catherization of a carotid artery and jugular vein) performing tracheotomies is convenient, with the additional advantage of minimized dead space $(\mathrm{Vd})$. A reliable surgical procedure for this airway access is briefly described: after induction of anesthesia the mouse is put into the supine position and the head is reclined (silk or rubber band around the upper incision teeth and attached to the operating surface) to allow easy access to the ventral neck. A median cerival skin incision (upper thorax aperture to lower jaw) is performed and layerwise skin, fascia, fat and connective tissue covering the thyroid gland are removed. The thyroid lobes are divided bluntly at their isthmus, pulled aside and kept retracted by bulldogclamps. The pretracheal muscles are spread bluntly and pulled aside to allow access to larynx and trachea. Tracheotomy is performed by a transversal cut between two tracheal rings, usually in the lower third of the trachea. For the endotracheal intubation vascular PE-catheters (Abbocath-T ${ }^{\circledR}$, Abbott-Venisystems) are used, cut to a length of about $5 \mathrm{~mm}$ with an angled tip $\left(45^{\circ}\right)$ to allow smooth introduction. The correct position of the endotracheal tube is confirmed by judging chest excursions, e.g., if respiration is still visible and symmetric. The tube is secured by ligation (silk 6-0, Davis \& $\mathrm{Geck}^{\circledR}$ ) around the trachea. If maintenance of spontaneous ventilation is desired, the endotracheal tube is shortened to minimize $\mathrm{Vd}$ and airway resistance. For mechanical ventilation, initially applied RR and/or Vt should be sufficiently higher than spontaneous RR and Vt of the anesthetized mouse to decrease respiratory drive (e.g., "breathing against the ventilator") by moderate hyperventilation. After connecting the endotracheal tube, anesthesia can be safely deepened for an additional depression of ventilatory drive and facilitation of mechanical ventilation. Alternatively, this goal can be achieved (avoiding additional cardiocirculatory depression) by a non-depolarizing muscle relaxant (vecuronium-bromid $0.25 \mathrm{mg} \cdot \mathrm{kg}^{-1}$ bodyweight i.p., Norcuron ${ }^{\circledR}$, Organon). Using this option it should be realized however that anesthesia depth cannot be judged from parameters like spontaneous movement or limb-withdrawal to paw pinch, but instead on changes in hemodynamics.

A side aspect of murine airway access is the preparation of a ventilated (and perfused) isolated lung. This model has been described for the investigation of cytokines released from a hyperventilated mouse lung (57). The physiological lung variables obtained from this murine model (female BALB/c, 22-30 $\mathrm{g}$ body weight) after $60 \mathrm{~min}$ of NPV (negative pressure ventilation) are a Vt $=187 \mu \mathrm{l}$, dynamic compliance (Cdyn) of $0.022 \mathrm{ml} / \mathrm{cmH}_{2} \mathrm{O}$ and an airway resistance of $0.45 \mathrm{~cm}$ $\mathrm{H}_{2} \mathrm{O} \cdot \mathrm{s} / \mathrm{ml}$.

\section{Mechanical ventilation of mice}

There are two basic modes of respiration, spontaneous ventilation and controlled mechanical ventilation (CMV), where work of breathing is taken over by the ventilator. Between these there are a variety of mixed forms, like respiratory assistance, augmenting inspiration if shallow or labored (RSP1002, Kent-Scientific ${ }^{\circledR}$, US) or supported spontaneous ventilation with continuous positive airway pressure (CPAP), adopted for mice by Brady and colleagues (3). However, these mixed modes are not largely established for mice yet, and will therefore not discussed in detail.

Although mechanical ventilation of mice has major advantages, it is confounded by difficulties: obviously, the small size of the animals makes airway access more challenging than in other laboratory animals. For example, in $25-30 \mathrm{~g}$ mice, the trachea has an accessible length of only $3-5 \mathrm{~mm}$ and a circumference of about $2.5 \mathrm{~mm}$ (49). Appropriate endotracheal tubes have an outher diameter ranging from $0.4 \mathrm{~mm}$ for neonate mice (30) to $1.0 \mathrm{~mm}$ for adult mice (13). The actual mechanical ventilation of the mouse is complicated by the technically demanding respiratory pattern of this species, e.g., the high RR, the low Ti/Tt ratio and the small Vt, with the latter also demanding a minimized deadspace (Vd) to prevent rebreathing. In commercially available rodent ventilators, the relatively large system-Vd allows substantial gas compression, thereby minimizing the $\mathrm{Vt}$ delivered to the mouse. Ewart et al. (11) reported that $2 \mathrm{ml}$ of added $\mathrm{Vd}$ (compliance $\sim 0.002 \mathrm{ml} / \mathrm{cmH}_{2} \mathrm{O}$ ) and a peak inspiratory pressure of $40 \mathrm{~cm}$ $\mathrm{H}_{2} \mathrm{O}$ reduce the delivered Vt by about $50 \%$. Thus, mouse ventilators (see Table 2) should have a range of technical modalities to enable proper murine ventilation. Since some authors did not report on the type of ventilator used (see Table 3) the list might be incomplete.

The most obvious difference between spontaneous respiration and usual modes of mechanical ventilation (MV) are inverted pressure relations, with respect to ambient pressure, during the respiratory cycle: during spontaneous inspiration the expansion of the intrathoracic volume (mainly caused by contraction of the diaphragm and extension of the rib cage) generates a negative intrathoracic pressure and allows gas flow into the lungs. During expiration mainly passive elastic forces of lung and rib cage generate a positive intrathoracic pressure, leading to exhalation of air. Applying usual MV, the air is pushed during inspiration into the mice's lungs, leading to a 
Table 2 Operation specifications of current mouse ventilators.

\begin{tabular}{lllcccc}
\hline Producer/Distributor & Product & Vt $[\mathrm{ml}]$ & RR $\left[\mathrm{min}^{-1}\right]$ & Pressure limited & PEEP-feature & Ti/Tt range \\
\hline CWE-Ardmore & Sar 830 pv & $0.1-35$ & $5-198$ & Yes & Yes & $0.01-0.99$ \\
AMC & MICU-2 & $0-10$ & $1-500$ & Yes & Yes & $0.1-0.9$ \\
BDO-Medipass & m.a.w. & $0.02-0.35$ & $60-400$ & Yes & Yes & 0.50 \\
Columbus Instr. & CIV-101 & $0.05-100$ & $5-200$ & Yes & Yes & $0.2-0.8$ \\
Harvard Instr.* & $60-1099$ & $0-300$ & $1-400$ & Yes & Yes & $0.05-0.45$ \\
Kent-Scientific & RSP-1002 & $0-300$ & $1-400$ & Yes & Yes & $0.05-0.45$ \\
UNO & UMV & $0-12$ & $25-220$ & Yes & Yes & 0.50 \\
\hline
\end{tabular}

$V t$ tidal volume, $R R$ respiratory rate, Ti/Tt inspiratory fraction. *Harvard Apparatus is also distributor of Hugo Sachs mouse ventilators.

positive intrathoracic pressure. During expiration intrathoracic pressure equilibrates with ambient pressure (intermittent positive pressure ventilation, IPPV) or remains positive (continuous positive pressure ventilation, CPPV). Therefore it is important to notice that mean airway pressure during mechanical ventilation is higher than during spontaneous ventilation. These higher pressures contribute to side effects induced by mechanical ventilation.

Mechanical ventilators are classified according to their method of cycling between the inspiratory and expiratory phases. Small animal ventilators are usually time-cycled: the ventilator switches between the respiratory phases after a certain time has elapsed, depending on the preset respiratory rate.
Although other methods of cycling might be favorable under certain experimental conditions (e.g., volume-cycled to prevent pulmonary volutrauma in murine open chest preparations), they are not established yet. However, although the method of cycling is classified according to a single parameter (e.g., time), some mouse respirators allow a more sophisticated control of the ventilation by limiting relevant parameters: to prevent high inspiratory peak airway pressures, for example, most mouse ventilators allow the limitation of the ventilatory system pressure. Most commercial mouse ventilators are time cycled and pressure limited.

The primary goal of mechanical ventilation is delivery of an adequate respiratory minute-volume (Ve) to the murine

Table 3 Parameters of mechanical ventilation in murine closed- and open-chest experiments.

\begin{tabular}{|c|c|c|c|c|c|c|c|}
\hline Mouse strain & bw $[\mathrm{g}]$ & Ventilator & $\mathrm{RR}\left[\mathrm{min}^{-1}\right]$ & $\mathrm{Vt}[\mathrm{ml}]$ & $\mathrm{Ti} / \mathrm{Tt}$ & Extra & Ref. [No.] \\
\hline C57 SV 129 & $7-8$ wk & Harvard & 150 & $5-6 \mu l \cdot \mathrm{g}^{-1}$ & $(?)$ & P 3-4 & (9) \\
\hline $\mathrm{nNOS}^{(-/-)}$ & $7-8 \mathrm{wk}$ & Harvard & 150 & $5-6 \mu \mathrm{l} \cdot \mathrm{g}^{-1}$ & $(?)$ & P 3-4 & (9) \\
\hline ICR & $35-42$ & Harvard & 150 & $0.28-0.34$ & $(?)$ & $\mathrm{P} \sim 3$ & (37) \\
\hline $\mathrm{A} / \mathrm{J}$ & 21.8 & custom & 120 & $0.17-0.2$ & (?) & (?) & (11) \\
\hline SV-129 & $19-31$ & CVE & $120-170$ & $0.35-0.45$ & $0.14-0.28$ & CG & (7) \\
\hline ICR & $35-46$ & CVE & 140 & 0.7 & 0.47 & (?) & (14) \\
\hline$(?)$ & $(?)$ & $(?)$ & 100 & 0.5 & $(?)$ & $(?)$ & (23) \\
\hline$(?)$ & (?) & Harvard & 100 & 0.5 & (?) & (?) & (22) \\
\hline $\mathrm{C} 3 \mathrm{H} / \mathrm{He}$ & 23.3 & custom & 120 & $0.17-0.2$ & (?) & (?) & (11) \\
\hline (?) & $(?)$ & Harvard & 130 & 1.0 & $(?)$ & $(?)$ & (2) \\
\hline $\mathrm{A} / \mathrm{J}$ & $15 \mathrm{wk}$ & custom & 60 & $4-7 \mu \mathrm{l} \cdot \mathrm{g}^{-1}$ & (?) & (?) & (59) \\
\hline $\mathrm{BALB} / \mathrm{c}$ & $15 \mathrm{wk}$ & custom & 60 & $4-7 \mu \mathrm{l} \cdot \mathrm{g}^{-1}$ & (?) & $(?)$ & (59) \\
\hline C57BL/6 & $15 \mathrm{wk}$ & custom & 60 & $4-7 \mu \mathrm{l} \cdot \mathrm{g}^{-1}$ & (?) & (?) & (59) \\
\hline $\mathrm{C} 3 \mathrm{H} / \mathrm{He}$ & $15 \mathrm{wk}$ & custom & 60 & $4-7 \mu \mathrm{l} \cdot \mathrm{g}^{-1}$ & (?) & (?) & (59) \\
\hline NIH MF 1 & $12-28$ & $(?)$ & 168 & $(?)$ & 0.21 & $\mathrm{P} \sim 2$ & (41) \\
\hline $129 \mathrm{SV} x \mathrm{ICR}$ & 38 & Sinano & $100-150$ & $0.2-0.4$ & $(?)$ & $\mathrm{CG}$ & (30) \\
\hline $\mathrm{ET}-1^{(+/-)}$ & 38.4 & Sinano & $100-150$ & $0.2-0.4$ & (?) & CG & (30) \\
\hline $\mathrm{BALB} / \mathrm{c}$ & $22-30$ & $(?)$ & 90 & 0.2 & (?) & (?) & (57) \\
\hline CD-1 & $35-40$ & Harvard & 120 & 0.5 & $(?)$ & (?) & (36) \\
\hline $\mathrm{BALB} / \mathrm{c}$ & young & $(?)$ & 40 & $(?)$ & 0.33 & $\mathrm{P} \sim 0$ & (50) \\
\hline FVB & $25-38$ & Harvard & 110 & $0.2-0.4$ & $(?)$ & $\mathrm{OC}$ & (29) \\
\hline ICR & 33 & Harvard & 105 & $2.1-2.5$ & (?) & $\mathrm{OC}$ & (18) \\
\hline BALB/e Ajc 1 & $19-27$ & Harvard & 90 & 0.8 & (?) & $\mathrm{OC}$ & (44) \\
\hline $\mathrm{C} 3 \mathrm{H} / \mathrm{HeJ}$ & $20-35$ & custom & 120 & 0.2 & (?) & $\mathrm{OC}$ & (15) \\
\hline
\end{tabular}

If bodyweight (bw) was unknown, the age is given in weeks [wk]. Vt is expressed in [ml], only if bodyweight was unknown, the Vt is expressed in $\left[\mu l \cdot \mathrm{g}^{-1}\right] . b w$ bodyweight, $R R$ respiratory rate, $V t$ tidal volume, Ti/Tt inspiratory fraction, $P$ PEEP pressure $\left[\mathrm{cmH}_{2} \mathrm{O}\right], R e f$. reference, $C G$ Capnography, $O C$ open chest 
lung. To achieve this, the RR and Vt have to be adjusted to supply the actual ventilatory requirements. RR in most mouse ventilators is the preset cycling parameter, but Vt-lung may vary, depending on the compliance of lungs and tubing and whether respiration is pressure limited. A decrease in compliance of the respiratory system, for example in murine models of interstitial pulmonary diseases (ARDS, pneumonia), increases the airway pressure for a given $\mathrm{Vt}_{\text {ventilator }}$. If ventilation is pressure limited, then $\mathrm{VT}_{\text {lung }}$ will be considerably less than $\mathrm{Vt}_{\text {ventilator }}$. In contrast, if higher peak pressures are accepted to maintain $\mathrm{Vt}_{\text {lung }}$, the risk to traumatize the delicate murine lung will increase (17). To prevent the occurrence of these high pressures, inspiration time relative to expiration can be increased for a given $\mathrm{Vt}$ (up to inverse ratio ventilation (IRV), with inspiration longer than expiration). Disadvantages of a higher inspiratory fraction during mechanical ventilation are possibly insufficient times for complete exhalation ("air trapping") and the prolonged phases of elevated intrathoracic pressure, which may cause a decreased cardiac preload and consequently lowered blood pressures (7).

A feature provided by some mouse-ventilators is the possible application of external positive end-expiratory airway pressure (PEEP): during expiration, airway pressure is not allowed to equilibrate with ambient pressure $\left(0 \mathrm{cmH}_{2} \mathrm{O}\right)$, but kept at a higher level (usually $2-10 \mathrm{cmH}_{2} \mathrm{O}$ ). Mechanical ventilation with PEEP prevents the endexpiratory collapse of small airways and possibly recruits atelectatic pulmonary areas for gas exchange by increase of functional residual capacity (FRC). Since pulmonary compliance increases (up to a certain degree) with increased FRC, ventilation with PEEP supports pulmonary inflation. Whether this holds true for mice has not been shown yet. Additionally, ventilation with PEEP might mimic the physiologic end-expiratory tonus of inspiratory muscles and glottis of spontaneous ventilating mice (56). Typical side effects, demonstrated in a murine model of PEEP, are discussed below.

A list of ventilator settings is given in Table 3. Most experiments have mechanical ventilation set at $\mathrm{RR}=100$ $150 \cdot \mathrm{min}^{-1}, \mathrm{Vt}=0.2-0.7 \mathrm{ml}, \mathrm{Ti} / \mathrm{Tt} 0.2-0.4$. When these values are compared to values of spontaneous ventilating mice (Table 1), it becomes obvious that lower RR and higher Vt are commonly used to mechanically ventilate mice.

A more rare feature provided by some mouse ventilators is the intermittent sigh-ventilation. Here an inspiration with higher tidal volume (hyperinflation- or sigh-cycle) is administered after a certain number of respiratory cycles (for example every 50 ventilatory cycles) or triggered manually (RSP-1002, Kent-Scientific ${ }^{\circledR}$ Corporation, Litchfield, CT, USA or 60 $1100 / 1099$, Harvard Instruments ${ }^{\circledR}$, US). Although not proven, this imitation of physiological sighing is thought to result in recruitment of atelectatic pulmonary areas, without the need for a continuous PEEP, circumventing constant elevation of airway pressures. Intermittent positive pressure ventilation
(IPPV) and continuous positive pressure ventilation (CPPV) are the two common modes in murine mechanical ventilation, as provided by commercial ventilators. However, for the ventilation of newborn mice (1.0-1.5 g bodyweight, Vt 5-20 $\mu \mathrm{l})$ the concept of the "iron lung", based on the principle of body surface negative pressure ventilation has been adopted (27) to prolong survival time of NMDA-receptor mutant mice (32), usually dying within $20 \mathrm{~h}$ after birth.

Only a few studies using mechanical ventilation in mice report on additional ventilatory parameters, like inspiratory gas flow or pressures in the ventilatory system. Using a RR of $140 \cdot \mathrm{min}^{-1}$, a Vt of $0.7 \mathrm{ml}$ and an inspiratory time of $0.2 \mathrm{~s}$ (resulting in a inspiratory fraction (Ti/Tt) of 0.41 , Table 3 ) Furukawa et al. (14) achieved with inspiratory flows of $200 \mathrm{ml} \cdot \mathrm{min}^{-1}$ an end-inspiratory pressures of $8-10 \mathrm{cmH}_{2} \mathrm{O}$. Yasue et al. (59) ventilated mice of different strains (A/J, $\mathrm{BALB} / \mathrm{c}, \mathrm{C} 57 \mathrm{BL} / 6$ and $\mathrm{C} 3 \mathrm{H} / \mathrm{He}$ ) with a rather low $\mathrm{RR}$ of $60 \cdot \mathrm{min}^{-1}$, a Vt of $7-10 \mathrm{ml} \cdot \mathrm{kg}^{-1}$ and maintained ventilatory pressures below $5 \mathrm{cmH}_{2} \mathrm{O}$. In general, it is reported that normal airflow pressures for mice should be in the range from $5-10 \mathrm{cmH}_{2} \mathrm{O}(24)$, although direct evidence for this range is lacking.

Data are also available on ventilation regimen for murine open-chest preparations: Guo et al. (18) compared respiratory rates of 95,105 and $121 \cdot \mathrm{min}^{-1}$ (Harvard rodent ventilator, room air with oxygen $\left(21 \cdot \mathrm{min}^{-1}\right), \mathrm{Vt}=2.2 \mathrm{ml}$ with endotracheal tube loosely connected) in male ICR mice (8-12 weeks old, mean body weight $33.3 \mathrm{~g}$ ) with respect to the resulting arterial blood gases. Adequate ventilation was obtained with a $\mathrm{RR}$ of $105 \cdot \mathrm{min}^{-1}$, resulting in an arterial $\mathrm{PaO} \mathrm{O}_{2}$ of $327 \mathrm{mmHg}$ (177 and $321 \mathrm{mmHg}$ for $95 \cdot \mathrm{min}^{-1}$ and $121 \cdot \mathrm{min}^{-1}$ respectively), an arterial $\mathrm{PaCO}$ of $31 \mathrm{mmHg}$ (43 and $18 \mathrm{mmHg}$ for $95 \cdot \mathrm{min}^{-1}$ and $121 \cdot \mathrm{min}^{-1}$ respectively) and an arterial $\mathrm{pH}$ of 7.4 (7.3 and 7.5 for $95 \cdot \mathrm{min}^{-1}$ and $121 \cdot \mathrm{min}^{-1}$ respectively). Other regimens for the ventilation of open chest mice are listed in Table 3 .

\section{Monitoring of mechanical ventilation}

During controlled mechanical ventilation (CMV), the most frequent applied mode of artificial respiration in mice, the work of breathing is taken over by the respirator. To facilitate this controlled mechanical ventilation (e.g., prevention of "breathing against the ventilator") it is usually performed under deep anesthesia. This ensures that relevant compensatory mechanisms (e.g., onset of spontaneous ventilation induced by hypercapnia or hypoxia) are impaired and underline the importance of monitoring mechanical ventilation. Attempts to monitor mechanical mouse ventilation are complicated by the fact that even standard variables for ventilation are not established yet or show conflicting results (see Table 1).

Several possibilities are applicable to monitor adequacy of ventilation. A highly subjective way, requiring experience, is 
to observe the thorax-excursions with respect to rate, amplitude, symmetry and regularity as indicators of ventilatory rate, tidal volume, endotracheal tube position and attempt to spontaneous ventilatory effort. Dalkara et al. (7) suggest for a physiological mouse ventilation (mean $\mathrm{PaCO}=35 \mathrm{mmHg}$ ) keeping "the volume at a level at which thoracic movements first become noticeably observed". Information on the oxygenation can be obtained from the ear and tailskin color, e.g., with cyanosis indicating poor oxygenation (desoxy-hemoglobin $5 \mathrm{~g} \cdot 100 \mathrm{ml}^{-1}$ ). These measures might serve as a first orientation in the evaluation of the adequacy of mechanical ventilation. More objective and in-depth measures are gas flows, airway pressures and partial pressures (see below).

\section{Respiratory gas flow}

The measurement of respiratory gas flow in mice has been a technical challenge, mainly because pneumotachographs attached to the endotracheal tube increase the ventilatory dead space (Vd). Recently pneumotachographs have been developed for mice that allow both direct airway gas flow measurement and plethysmography (Kent-Scientific ${ }^{\circledR}$ Small Animal Pneumotachs, TRN3100, Kent Scientific Corporation). But even modern devices in this setting are suspected to increase dead space to a crucial extent, leading to partial rebreathing and consequently to hypercapnia and eventually hypoxia.

\section{Airway pressures}

The direct, non-invasive measurement of murine airway pressures is technically difficult; therefore, substitutes have been established to obtain estimates. In commercially available mouse ventilators, the airway pressures are measured inside the ventilator. The advantage of this construction is that it circumvents the need for an additional pressure transducing line, ideally originating from the endotracheal tube itself, to a pressure transducer. A major disadvantage however is that pressures measured in the ventilator need to be extrapolated to airway pressures within the endotracheal tube. This extrapolation is determined by the compliance of the respiratory gases and the tubing system ("signal damping"). It is therefore desirable to measure airway pressures as close as possible to the endotracheal tube. With respect to this, we have developed an integrated endotracheal tube within a small aluminum frame (10 x 5 x $2 \mathrm{~mm}, 5 \mathrm{~g}$ ), consisting of temperature controlled adapters for in- and expiratory tubing, an inline-capnography cell ( $\mathrm{Vd}$ $=25 \mu \mathrm{l})$ and a liquid-filled airway-pressure transducer. Although airway pressures are usually monitored to maintain safe values for mean- and peak-airway pressure, this measure can also serve to titrate damage in murine models of respirator-induced lung impairment, such as baro- or volutrauma
(17), where tidal volumes (Vt) have been adjusted to achieve traumatizing target airway pressures.

\section{Partial pressures of gasses}

Fresh-gas inflow composition to the mechanical ventilator can be monitored with respect to the concentrations of the different respiratory gases, e.g., oxygen $\left(\mathrm{O}_{2}\right)$, nitrogen $\left(\mathrm{N}_{2}\right)$, nitrous oxide $\left(\mathrm{N}_{2} \mathrm{O}\right)$ and volatile anesthetics. When rebreathing of exhaled air is excluded in the ventilatory circuit, analysis of fresh gas streaming to the respirator should accurately reflect the composition of inspiratory gases. This attempt is advantageous, compared to sample lines attached to the inspiratory tubing-limb of the system, because it circumvents the need for gas extraction from the inspiratory tubing with the consequence of decreased inspiratory airways-pressures and ventilatory tidal volumes. The actual measurement can be performed online with commercially available multi-gas analyzers $\left(\right.$ Datex $\left.{ }^{\circledR}, \mathrm{HP}^{\circledR}\right)$. It has been argued that ventilation with room air may not be ideal in mice (24), based on observed high murine $P_{50}$ values $\left(\mathrm{PO}_{2}\right.$ corresponding to $50 \%$ hemoglobin saturation) of $65 \mathrm{mmHg}$ (46) or even $71 \mathrm{mmHg}$ (48). However, most studies have found a $P_{50} \sim 40 \mathrm{mmHg}$ for the mouse, when measured under standard conditions $\left(\mathrm{pH}=7.4, \mathrm{PCO}_{2}=\right.$ $\left.40 \mathrm{mmHg}, 37^{\circ} \mathrm{C}\right)(25,31,35,42,47)$. A $P_{50}$ of $\sim 40 \mathrm{mmHg}$ is still rightshifted, when compared to humans $\left(P_{50}=28 \mathrm{mmHg}\right)$. Nevertheless, although even with a high $P_{50} \sim 65 \mathrm{mmHg}$ blood is virtually $100 \%$ saturated at room air (46), increased $\mathrm{FiO}_{2}$ may be helpful in the mouse when uncertainty exists whether mechanical ventilation optimally expands the lungs.

If volatile anesthetics (halothane, enflurane, isoflurane or more recent ones such as sevoflurane and desflurane) are used, additional considerations have to be taken into account: clinically used vaporizers for volatile anesthetics $\left(\right.$ Draeger $^{\circledR}$, series 19) are usually precalibrated for gas flows higher than that required for mice and will therefore give unreliable results when used with low gas flows. Although recalibration of the vaporizer for low air-flow is the best option, a more common approach is to use an appropriate high gasflow (several hundred $\mathrm{ml} \cdot \mathrm{min}^{-1}$ ) with the abundant air released via a T-type adapter or valve. Disadvantages of the latter approach are higher costs and the generation of relatively large amounts of waste gas giving environmental contamination and increased toxicity for exposed personnel.

In contrast to maintenance of sufficient arterial oxygenation, which even under conditions of poor ventilatory support can be achieved by an increased fraction of inspiratory oxygen $\left(\mathrm{FiO}_{2}\right)$, adequate pulmonary elimination of $\mathrm{CO}_{2}$ is the more challenging aspect of mechanical ventilation. Although the arterial blood gas analysis is regarded as the gold standard for evaluation of proper ventilation, the drawbacks are that it is a discontinuous and invasive method requiring a substantial vol- 
ume of arterial blood $(0.1-0.2 \mathrm{ml}$ for a single measurement, $5-10 \%$ of the total blood volume of a $25 \mathrm{~g}$ mouse (58)), the latter aspect adding new sources of instability to the model. Though often neglected, measurement of respiratory carbon dioxide concentration (capnography) is therefore recommended in mouse research. Especially the determination of the end-tidal $\mathrm{CO}_{2}\left(\mathrm{etCO}_{2}\right)$, as a measure for alveolar $\mathrm{CO}_{2}$-concentration, is described as essential to maintain stable physiological parameters during mechanical mouse ventilation (7). However, capnography has rarely been performed in mice due to technical difficulties, like gas dilution artifacts occurring in side stream systems, which prevent accurate detection of endtidal $\mathrm{CO}_{2}$-peaks or-plateaus. Therefore, to use the potential of capnography to its full extent, fast responding mainstreamcapnography is required. To this end we have developed an integrated mouse endotracheal tube with an implemented capnography-cell with minimal gas-mixing artifacts. Since this cell is located in the endotracheal tube it allows real-time in- and expiratory mainstream breath-by-breath capnography. A typical capnography curve using this device is shown in Fig. 1 , showing several single breath capnography curves (inner section with high chart speed, RR $\sim 100 \mathrm{~min}^{-1}$ ).

Capnography is not only a measure for the adequacy of mechanical ventilation, but can also serve to detect changes in hemodynamics. An example for this is given in Fig. 2: during steady-state anesthesia $0.2 \mathrm{ml}$ blood was withdrawn from an arterial line (black arrow). The end-tidal carbon dioxide concentration drops immediately, likely due to a decrease in pulmonary perfusion (decreased cardiac output). Resuscitation is performed by rapid infusion of $0.2 \mathrm{ml}$ albumin solution (white arrow), which increased capnography values back to baseline, probably by restoring pulmonary perfusion. Since time resolution is enhanced by our breath-by-breath capnography, the relation between expiratory $\mathrm{CO}_{2}$ and specific events can be described precisely. Additionally, the capnography curves can

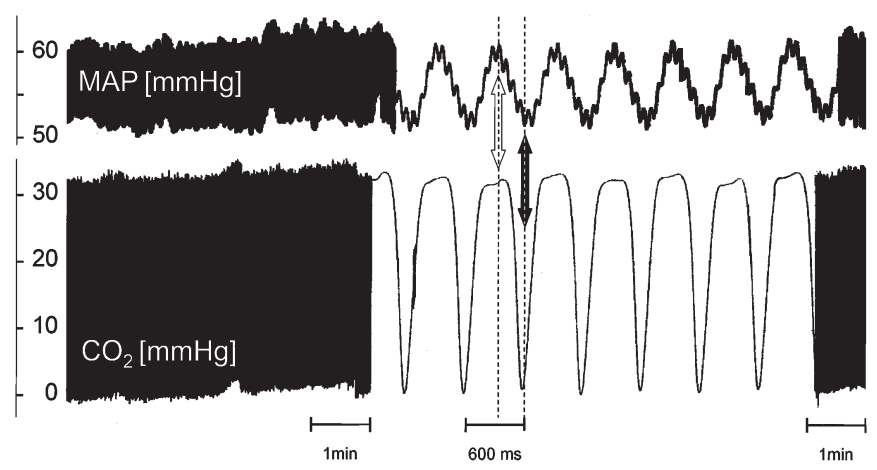

Fig. 1 Capnography $\left(\mathrm{CO}_{2}\right)$ and mean arterial pressure (MAP) during mechanical ventilation of a mouse (C57BL/6, $23 \mathrm{~g})$. Note the correspondence of respiratory phase and systemic hemodynamic effect (black arrow $=$ end inspiratory, white arrow $=$ end expiratory). For details see text.

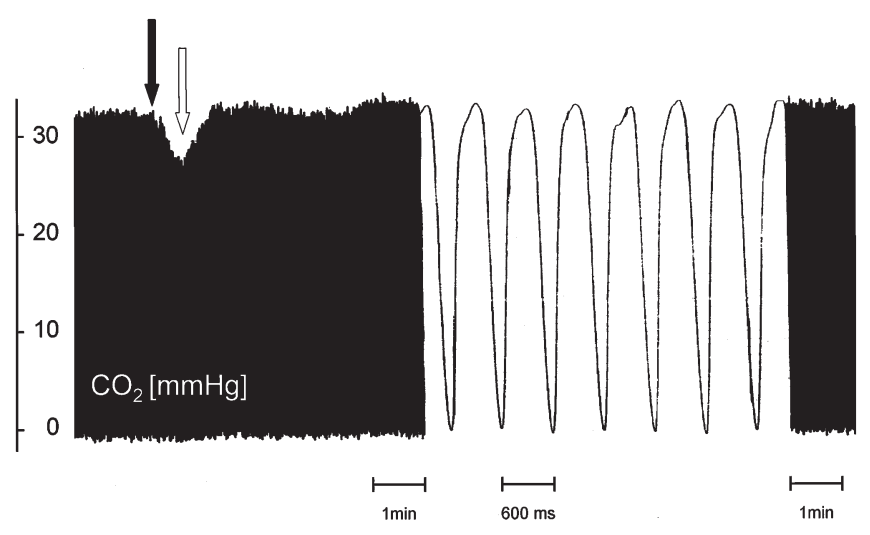

Fig. 2 Effect of blood withdrawal ( $0.2 \mathrm{ml}$, black arrow) and immediate resuscitation with albumin solution $(0.2 \mathrm{ml}$, white arrow) on capnography. For details see text.

be analyzed with respect to irregularity (e.g., due to intermittent spontaneous breathing) and shape alterations (e.g., airway obstruction).

A few mouse capnographs are commercially available, mostly using side stream sampling (e.g., Kent Scientific Corporation SC-210 respiratory $\mathrm{CO}_{2}$ monitor). The only main stream capnograph commercially available for mice to our knowledge is the SC-300 (Kent-Scientific Corporation) with an external $\mathrm{CO}_{2}$-probe to be placed in the ventilation tubing. However, we were unable to find studies reporting on this device. A disadvantage of this device, as reported by the manufacturer, is that RR is limited to $150 \mathrm{~min}^{-1}$, which might not meet the demands of all experimental designs (Table 3 ).

\section{Side effects of mechanical mouse-ventilation}

The enhanced stability of the murine homeostasis is a major goal of mechanical ventilation, but typical side effects have to be considered, possibly adding new sources of instability to the murine model. These side effects can be classified as regional (airways and lungs affected) or systemic (distant organs affected). A typical example for a ventilator-induced regional side effect is the mechanical hyperinflation of the murine lung, e.g., when large tidal volumes or high airway pressures are applied. This induces histological damage of the delicate murine pulmonary structures. This volutrauma has been shown in mice to trigger the onset of inflammation, including expression of cytokines (57).

The systemic side effects of mechanical ventilation are (at least partly) due to a compromised hemodynamic situation. Mechanical ventilation per se results in larger intrapulmonary pressures as compared to spontaneous ventilation, possibly inhibiting venous return to the heart. In addition, prolonged phases of positive airway pressures, e.g., when the inspiratory fraction $(\mathrm{Ti} / \mathrm{Tt})$ is increased or when external PEEP is applied, 


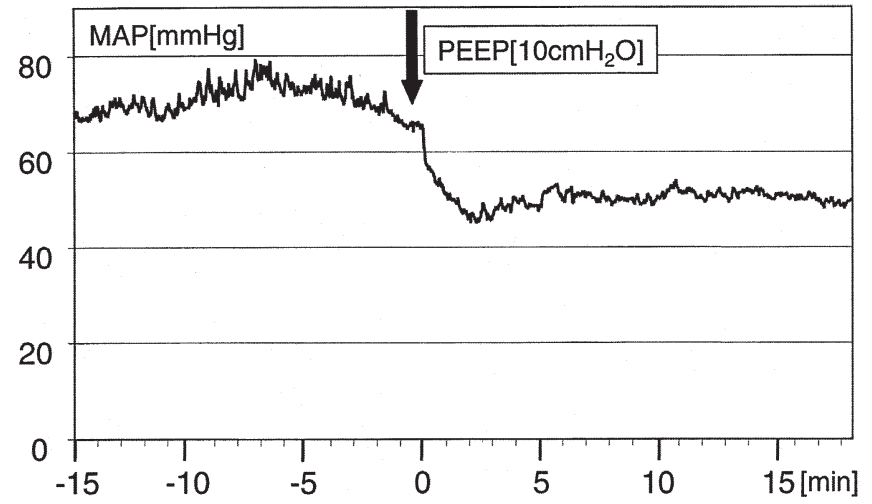

Fig. 3 Effect of mechanical ventilation with PEEP $\left(10 \mathrm{cmH}_{2} \mathrm{O}\right)$ on arterial blood pressure (C57BL/6, $22 \mathrm{~g})$. For details see text.

depresses the circulation by several mechanisms, also via an impaired venous return to the heart. As an example for a global hemodynamic variable, arterial blood pressure decreases immediately after application of higher levels of PEEP: Fig. 3 shows a typical blood pressure trace of a deeply anesthetized mouse (C57BL/6, $25 \mathrm{~g}$ bodyweight, anesthesia with ketamine $\left(35 \mathrm{mg} \cdot \mathrm{kg}^{-1} \cdot \mathrm{h}^{-1}\right)$ and medetomidine $\left(35 \mu \mathrm{g} \cdot \mathrm{kg}^{-1} \cdot \mathrm{h}^{-1}\right)$ indicating the immediate hypotensive reaction after application of $10 \mathrm{cmH}_{2} \mathrm{O}$ PEEP. The extent of hypotension induced by mechanical ventilation is further related to the respiratory phase, as demonstrated in Fig. 1, a simultaneous recording of capnography and arterial blood pressure in a C57BL/6mouse (anesthetized with fentanyl $\left(0.8 \mathrm{mg} \cdot \mathrm{kg}^{\cdot-1} \cdot \mathrm{h}^{-1}\right)$, fluanison (25 $\mathrm{mg} \cdot \mathrm{kg}^{-1} \cdot \mathrm{h}^{-1}$ ) and midazlam $\left(3 \mathrm{mg} \cdot \mathrm{kg}^{-1} \cdot \mathrm{h}^{-1}\right)$, a more hypotensive anesthesia than used in Fig. 3, explaining the different baseline blood pressures). At end-expiration (white arrow), where intrathoracic pressure is minimal, arterial blood pressure reaches its peak value and vice versa (black arrow).
A second example for side effects of the mechanical ventilation with PEEP distant to the lung is the impairment of the intestinal microcirculation. In anesthetized C57BL/6-mice (terminal ileum exposed) we were able to visualize a marked reduction of perfused capillaries and a decrease in capillary blood flow velocity, using orthogonal polarized spectral (OPS-) imaging (16). Figure 4 A/B shows a typical example for PEEP-induced microcirculatory impairment. Both images show the same intestinal region, before (4A) and 15 minutes after (4B) onset of $5 \mathrm{cmH}_{2} \mathrm{O}$ external PEEP, with white arrowheads marking corresponding capillaries (black) in both images. In contrast to Fig. 4A the capillaries in 4B are markedly less numerous and appear dashed, indicating erythrocyte aggregations formed at low capillary blood flow velocities.

\section{Conclusion}

Respiratory control of mice is a field of growing interest. Although spontaneous ventilation is the more physiological mode of breathing, only mechanical ventilation maintains physiological values (blood gases, acid-base status) in situations with impaired spontaneous breathing, as occurring during anesthesia, surgery or constitutively in murine strains with impaired spontaneous ventilation. There are currently several commercially available small rodent ventilators feasible for use in mice. If mechanical ventilation is performed, then monitoring of this intervention is required, ideally by means of capnography. Research still has to be performed on how the most physiological ventilation can be achieved in mice, which ventilatory patterns are appropriate and how ventilation related side effects can be limited.
Fig. 4 Effects of ventilation with PEEP on the murine intestinal microcirculation. A recorded before and $\mathbf{B} 15$ minutes after onset of PEEP $\left(5 \mathrm{cmH}_{2} \mathrm{O}\right)$. White arrowheads indicate corresponding capillary structures in both images. For details see text.
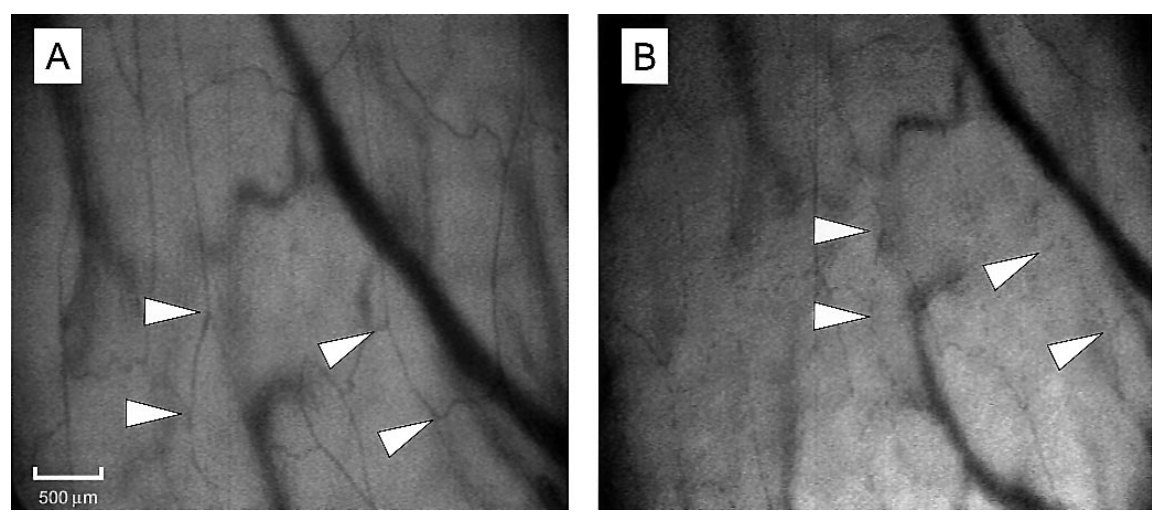


\section{References}

1. Balkowiec A, Katz DM (1998) Brain derived neurotropic factor is required for normal development of the central respiratory rhythm in mice. J Physiol 510 (Pt 2): 527-533

2. Berul CI, Mendelsohn ME (1998) In vivo electrophysiologic studies in mice. In: Hoit BD, Walsh RA (eds) Cardiovascular Physiology in the Genetically Engineered Mouse. Kluwer Academic Publishers, Norwell, MA, pp 161-181

3. Brady JF, Newsom DB (1966) Effect of positive pressure breathing on the vibration tolerance of mice. Aerospace med 37 (1): 40-45

4. Burton MD, Kawashima A, Brayer JA, Kazemi H, Shannon DC, Schuchardt A, Costantini F, Pachnis V, Kinane TB (1997) RET-protooncogene is important for the development of respiratory $\mathrm{CO} 2$ sensitivity. J Auton Nerv System 63 (3): 137-143

5. Crosfill ML, Widdicombe JG (1961) Physiological characteristics of the chest and lungs and the work of breathing in different mammalian species. J Physiol 158: 1-14

6. Currie WD, van Schaik S, Vargas I, Enhorning G (1998) Breathing and pulmonary surfactant function in mice $24 \mathrm{~h}$ after ozone exposure. Eur Respir J 12: 288-293

7. Dalkara T, Irikura K, Huang Z, Panahian N, Moskowitz MA (1995) Cerebrovascular responses under controlled and monitored physiological conditions in the anesthetized mouse. J Cerebr Blood Flow Metab 15 (4): 613-618

8. Dauger S, Nsegbe E, Vardon G, Gaultier C, Gallego J (1998) The effect of restraint on ventilatory response to hypercapnia and hypoxia in adult mice. Respir Physiol 112 (2): $215-225$

9. De Sanctis GT, Mehta S, Kobzik L, Yandava C, Jiao A, Huang PL, Drazen JM (1997) Contribution of type I NOS to expired gas $\mathrm{NO}$ and bronchial responsiveness in mice. Am J Physiol 273 (4 Pt 1): L883-888

10. Enhorning G, van Schaik S, Lundgren C, Vargas I (1998) Whole body plethysmography, does it measure tidal volumes of small animals? Can J Physiol Pharmacol 76: 945-951

11. Ewart S, Levitt R, Mitzner W (1995) Respiratory system mechanics in mice measured by end-inflation occlusion. J Appl Physiol 79 (2): 560-566

12. Fairchild GA (1972) Measurement of respiratory volume for virus retention studies in mice. Appl Microbiol 24: 812-818

13. Flecknell PA (1993) Anaesthesia of animals for biomedical research. Br J Anaesth 71: 885-894
14. Furukawa S, MacLennan MJ, Keller BB (1998) Hemodynamic response to anesthesia in pregnant and nonpregnant ICR mice. Lab Animal Sci 48 (4): 357-363

15. Georgakopoulos D, Mitzner WA, Chen C-H, Byrne BJ, Millar HD, Hare JM, Kass DA (1998) In vivo left ventricular pressurevolume relations by miniaturized conductance micromanometry. Am J Physiol 274: H1416-H1422

16. Groner W, Winkelman JW, Harris AG, Ince C, Bouma GJ, Messmer K, Nadeau RD (1990) Orthogonal polarization imaging: a new method for study of the microcirculation. Nature Medicine 5 (10): 1209-1213

17. Gronski T Jr, Lum E, Campbell J, Shapiro SD (1999) A murine model of volutrauma: potential contribution of inflammatory cell proteases to lung injury. Chest 166 (1S): $28 \mathrm{~S}$

18. Guo Y, Wu WJ, Qiu Y, Tang X-L, Yang Z, Bolli R (1998) Demonstration of an early and a late phase of ischemic preconditioning in mice. Am J Physiol 275 (44): H1375-H1387

19. Guyton AC (1947) Measurement of respiratory volumes of laboratory animals. Am J Physiol 150: 70-77

20. Harkness JE, Wagner JE (1990) The Biology and Medicine of Rabbits and Rodents, Cambridge University Press Cambridge

21. Herz U, Braun A, Ruckert R, Renz H (1998) Various immunological phenotypes are associated with increased airway responsiveness. Clin Exp Allergy 28 (5): 625-634

22. Hoit BD (1988) Invasive hemodynamic studies in open and closed chest mice. In: Hoit BD, Walsh RA (eds) Cardiovascular Physiology in the Genetically Engineered Mouse. Kluwer Academic Publishers, Norwell, MA, pp 111-124

23. Kadambi VJ, Kranias EG (1998) Transgenic models of cardiovascular physiology and pathology. In: Hoit BD, Walsh RA (eds) Cardiovascular Physiology in the Genetically Engineered Mouse. Kluwer Academic Publishers, Norwell, MA, pp 37-53

24. Kass DA, Hare JM, Georgakopoulos D (1998) Murine cardiac function - a cautionary tail. Circ Res 82 (4): 512-522

25. Khandelwal SR, Randad RS, Lin PS, Meng H, Pittman RN, Kontos HA, Choi SC, Abraham DJ, Schmidt-Ullrich R (1993) Enhanced oxygenation in vivo by allosteric inhibitors of hemoglobin saturation. Am J Physiol 265: H1450-H1453

26. Kline DD, Yang T, Huang PL, Prabhakar NR (1998) Altered respiratory responses to hypoxia in mutant mice deficient in neuronal nitric oxide synthase. J Physiol 511 (1): 273-287
27. Kolandaivelu K, Poon CS (1998) A miniature mechanical ventilator for newborn mice. J Appl Physiol 84 (2): 733-739

28. Kravchuk LA (1966) Method of artificial respiration in curarized mice. Biulleten Exsperimentalnoi Biologii I Meditsiny. 31 (11): 117-119

29. Kubota T, Mahler CM, McTiernan CF, Wu CC, Feldman MD, Feldman AM (1998) End-systolic pressure-dimension relationship of in situ mouse left ventricle. J Mol Cell Cardiol 30: 357-363

30. Kuwaki T, Cao W-H, Kurihara H, Ling G-Y, Onodera M, Ju KH, Yoshio Y, Kumada M (1996) Impaired ventilatory responses to hypoxia and hypercapnia in mutant mice deficient in endothelin-1. Am J Physiol 270 (39): R1279-R1286

31. Lahiri S, Daise M, Mokashi A (1975) Blood oxygen affinity and alveolar ventilation in relation to body weight in mammals. Am J Physiol 229 (2): 529-536

32. Li Y, Erzurumlu RS, Chen C, Jhaveri S, Thonegawa S (1994) Whisker-related neuronal patterns fail to develop in the trigeminal brainstem nuclei of NMDAR1 knockout mice. Cell 76: 427-437

33. Mathier MA, Asai K, Shannon RP, Vatner SG (1998) Cardiovascular physiology in mice. In: Hoit BD, Walsh RA (eds) Cardiovascular Physiology in the Genetically Engineered Mouse. Kluwe Academic Publishers, Norwell, MA, pp 111-124

34. Mortola JP, Lanthier C (1996) The ventilatory and metabolic response to hypercapnia in newborn mammalian species. Respir Physiol 103 (3): 263-270

35. Mouneimne Y, Barhoumi R, Myers T, Slogoff S, Nicolau C (1990) Stable rightward shifts of the oxyhemoglobin dissociation curve induced by encapsulation of inositol hexaphosphate in red blood cells using electrophoration. FEBS letters 275 $(1,2): 117-120$

36. Murakami K, Kondo T, Kawase M, Chan PH (1998) The development of a new mouse model of global ischemia. Brain Res 780: 304-310

37. Nagase T, Matsui H, Aoki T, Ouchi Y, Fukuchi Y (1996) Lung tissue behavior in the mouse during constriction induced by methacholine and endothelin-1. J Appl Physiol 81 (6): 2373-2378

38. Nielson GD, Petersen SH, Vinggaard AM, Hansen LF, Wolkoff P (1993) Ventilation, $\mathrm{CO} 2$-production, and $\mathrm{CO} 2$-exposure effects in conscious, restrained $\mathrm{CF}-1$ mice. Pharmacology \& Toxicology 72 (3): 163-168 
39. D'Donnel CP, Schaub CD, Haines AS, Berkowitz DE, Tankersley CG, Schwartz AR, Smith PL (1999) Leptin prevents respiratory depression in obesity. American Journal of Respiratory \& Critical Care Medicine 159 (5 Pt 1): 1477-1484

40. Onodera M, Kuwaki T, Kumada M, Masuda Y (1997) Determination of ventilatory volume in mice by whole body plethysmography. Jap J Physiol 47 (4): 317-326

41. Paton JFR, Butcher JW (1998) Cardiovascular reflexes in mice. Journal of the Autonomic Nervous System 68: 115-124

42. Petschow R, Petschow D, Bartels R, Baumann R, Bartels H (1978) Regulation of oxygen affinity in blood of fetal, newborn and adult mouse. Respir Physiol 35: 271-282

43. Schuessler TF, Bates JHT (1995) A computer-controlled research ventilator for small animals: design and evaluation. Trans Biomed Eng 42 (9): 861-866

44. Sakamoto J, Miura T, Tsuchida A, Fukuma T, Hasegawa T, Shimamoto K (1999) Reperfusion arrhythmias in the murine heart: their characteristics and alteration after ischemic preconditioning. Bas Res Cardiol 94: 489-495

45. Schmidt-Nielsen K (1984) Scaling: Why is Animal Size So Important? Cambridge University-Press, pp 100-101

46. Schmidt-Nielsen K, Larimer JL (1958) Oxygen dissociation curves of mammalian blood in relation to body size. Am J Physiol 195: 424-428
47. Shimizu S, Sakata S, Enoki Y, Ogha Y, Oki I, Kohzuki H (1989) Temporal change of plasma erythropoetin level in hypobaric hypoxic mice and the influence of an altered blood oxygen affinity. Jap J Physiol 39: 833-846

48. Shonat RD, Wachman ES, Niu W, Koretsky AP, Farkas DL (1998) Near simultaneous hemoglobin saturation and oxygen tension maps in the mouse cortex during amphetamine stimulation. In: Hudetz Bruley (eds) Oxygen Transport to Tissue 20, Plenum Press, New York, pp 149-159

49. Sutliff RL, Pau. RJ (1998) Mouse smooth muscle studies using gene-altered mouse models. In: Cardiovascular Physiology in the Genetically Engineered Mouse. Kluwer Academic Publishers, Norwell, MA, pp 247-259

50. Suzuki Y, Robertson B, Fujita Y, Grossmann G, Kogishi K, Curstedt T (1992) Lung protein leakage in respiratory failure induced by a hybridoma making monoclonal antibody to the hydrophobic surfactant-associated polypeptide SP-B. Int J Exp Path 73: 325-333

51. Tankersley CG, Fitzgerald RS, Kleeberger SR (1994) Differential control of ventilation among inbred strains of mice. Am J Physiol 267 (36): R1371-R1377

52. Tankersley CG, O'Donnel C, Daood MJ, Watchko JF, Mitzner W, Schwartz A, Smith P (1998) Leptin attenuates respiratory complications associated with the obese phenotype. J Appl Physiol 85 (6): 2261-2269
53. Tenny SM, Morrison DH (1967) Tissue gas tension in small wild mammals. Respir Physiol 3: 160-165

54. Tenny SM, Remmers JE (1963) Comparative quantitative morphology of the mammalian lung: diffusing area. Nature 197: $54-56$

55. Uechi M, Asai K, Osaka M, Smith A, Sato $\mathrm{N}$, Wagner TE, Ishikawa Y, Hayakawa H, Vatner DE, Shannon RP, Homcy CJ, Vatner SF (1998) Depressed heart rate variability and arterial baroreflex in conscious transgenic mice with overexpression of cardiac Gs-alpha. Circ Res 82: 416-423

56. Vinegar A, Sinnet EE, Leith DE (1979) Dynamic mechanisms determine functional residual capacity in mice, Mus musculus. J Appl Physiol 46: 867-871

57. Von Bethmann AN, Brasch F, Nusing R, Vogt K, Volk HD, Muller KM, Wendel A, Uhlig S (1998) Hyperventilation induces release of cytokines from perfused mouse lung. Am J Respiratory \& Critical Care Medicine 157 (1): 263-272

58. Wish L, Furth J, Storey RH (1950) Direct determination of plasma, cell, and organ blood volumes in normal and hypervolemic mice. Proc Soc Exp Biol Med 74: 644-648

59. Yasue M, Yokota T, Suko M, Okudaira H, Okumura Y (1998) Comparison of sensitization to scrude and purified house dust mite allergens. Lab Animal Sci 48 (4): $347-352$ 